\title{
Injectable interferon beta- Ib for the treatment of relapsing forms of multiple sclerosis
}

\author{
This article was published in the following Dove Press journal: \\ Journal of Inflammation Research \\ 15 March 2010 \\ Number of times this article has been viewed
}

\author{
Slobodan M Jankovic \\ Pharmacology Department, \\ Medical Faculty, University of \\ Kragujevac, Kragujevac, Serbia
}

Correspondence: Slobodan M Jankovic Medical Faculty, University of Kragujevac, Ul. Svetozara Markovica 69, 34000

Kragujevac, Serbia, Yugoslavia

Tel +38 I 34306800 Ext. I I7

Fax +38 I 34370073

Email slobnera@eunet.rs

\begin{abstract}
Multiple sclerosis (MS) is chronic inflammatory and demyelinating disease with either a progressive $(10 \%-15 \%)$ or relapsing-remitting $(85 \%-90 \%)$ course. The pathological hallmarks of MS are lesions of both white and grey matter in the central nervous system. The onset of the disease is usually around 30 years of age. The patients experience an acute focal neurologic dysfunction which is not characteristic, followed by partial or complete recovery. Acute episodes of neurologic dysfunction with diverse signs and symptoms will then recur throughout the life of a patient, with periods of partial or complete remission and clinical stability in between. Currently, there are several therapeutic options for MS with disease-modifying properties. Immunomodulatory therapy with interferon beta-1b (IFN- $\beta 1 \mathrm{~b})$ or $-1 \mathrm{a}$, glatiramer and natalizumab shows similar efficacy; in a resistant or intolerant patient, the most recently approved therapeutic option is mitoxantrone. IFN- $\beta 1 \mathrm{~b}$ in patients with MS binds to specific receptors on surface of immune cells, changing the expression of several genes and leading to a decrease in quantity of cell-associated adhesion molecules, inhibition of major histocompatibility complex class II expression and reduction in inflammatory cells migration into the central nervous system. After 2 years of treatment, IFN- $\beta 1 \mathrm{~b}$ reduces the risk of development of clinically defined MS from $45 \%$ (with placebo) to $28 \%$ (with IFN- $\beta 1 \mathrm{~b}$ ). It also reduces relapses for $34 \%$ (1.31 exacerbations annually with placebo and 0.9 with higher dose of IFN- $\beta 1 \mathrm{~b}$ ) and makes $31 \%$ more patients relapse-free. In secondary-progressive disease annual rate of progression is $3 \%$ lower with IFN- $\beta 1 \mathrm{~b}$. In recommended doses IFN- $\beta 1 \mathrm{~b}$ causes the following frequent adverse effects: injection site reactions (redness, discoloration, inflammation, pain, necrosis and non-specific reactions), insomnia, influenza-like syndrome, asthenia, headache, myalgia, hypoesthesia, nausea, paresthesia, myasthenia, chills and depression. Efficacy of IFN- $\beta 1 \mathrm{~b}$ in relapsing-remitting MS is higher than that of IFN- $\beta 1 \mathrm{a}$, and similar to the efficacy of glatiramer acetate. These facts promote IFN- $\beta 1 \mathrm{~b}$ as one of the most important drugs in the spectrum of immunological therapies for this debilitating disease.
\end{abstract}

Keywords: multiple sclerosis, interferon beta 1b, mechanism of action, efficacy, safety

\section{Introduction}

Multiple sclerosis (MS) is chronic inflammatory and demyelinating disease with either progressive $(10 \%-15 \%)$ or relapsing-remitting $(85 \%-90 \%)$ course. Essential for diagnosis of its relapsing-remitting form is dissemination of clinical episodes in time (two or more episodes) and space (more than one focal lesion). Nowadays, diagnosis is routinely confirmed by magnetic resonance imaging, the diagnostic test with $95 \%$ sensitivity. ${ }^{1}$

Prevalence of MS varies geographically, and is more common in Western European and North American countries. ${ }^{2}$ The most recent estimation of prevalence 
in USA was 100 symptomatic MS patients per 100,000 inhabitants, ${ }^{3}$ and prevalence in England is even higher $(118 / 100,000) .{ }^{4}$ Prevalence of MS in the Middle East is much lower, ranging from 4/100,000 in Saudi Arabia and Libya to $39 / 100,000$ in Jordan and 31.15/100,000 in Kuwait. ${ }^{5}$ Low prevalence was also recorded in Panama $(5.2 / 100,000),{ }^{6}$ with a female:male ratio of $8: 1$. Data on prevalence of MS are not available for the majority of Asian countries; however, a study from Japan reported a prevalence of $8.57 / 100,000$, and studies in the Parsi community in India showed a prevalence of 21 to 58/100,000 inhabitants. ${ }^{7}$ Such incomplete data led to a conclusion that prevalence of MS increases with latitude in both hemispheres, ${ }^{2}$ but with obvious exceptions, like Israel (with MS prevalence of 46.2/100,000), ${ }^{7}$ suggesting that prevalence of MS in a country depends more on national and racial origin of its inhabitants than on its latitude.

The male:female ratio among patients with MS ranges from 2.4:1 in Spain, ${ }^{8}$ through 1.64:1 in Israel, ${ }^{7} 1: 2.25$ in India $^{7}$ and $1: 2.3$ in Norway, ${ }^{9}$ to $1: 5$ in Malaysia ${ }^{7}$ and $1: 8$ in Panama. ${ }^{6}$ Average age of onset is between 25 and 35 years of age (32.6 years in Spain, ${ }^{8} 33$ years in Japan, ${ }^{7} 29$ years in China, ${ }^{7} 27$ years in India, ${ }^{7}$ and 34.7 years in Kuwait $^{7}$ ).

\section{Pathology and pathogenesis of MS}

Both genetic background and environmental events are involved in the pathogenesis of MS. If a family member is affected by MS, the risk for his/her cousins to develop the disease increases in proportion to the shared genetic information between themselves and the affected person. ${ }^{10}$ If a monozygotic twin develops MS, his/her brother or sister have 200 times greater risk of developing MS than members of the general population. Among the environmental factors, vitamin D deficiency and Epstein-Barr virus infection were the only ones for which causal links with MS were confirmed. ${ }^{10,11}$

The pathological hallmarks of MS are lesions of both white and grey matter in the central nervous system. ${ }^{12}$ Early in our understanding MS, it was considered that myelin-specific, activated CD4+ T lymphocytes migrate from blood to brain tissue, bind to antigenic peptides presented by antigen presenting cells in the brain, clonally expand, and then attack oligodendrocytes, destroying myelin. ${ }^{13}$ Now we know that neurons degenerate in the gray matter as well, and that this process is a major pathological correlate of clinical disability. ${ }^{13}$ Neurons die due to loss of myelin protection, direct toxic action of immune cells, diminution of trophic support, metabolic changes and altered signaling. ${ }^{13}$

\section{Clinical course of MS}

The onset of the disease is usually around 30 years of age. The patients experience an acute focal neurologic dysfunction which is not characteristic, followed by partial or complete recovery. Acute episodes of neurologic dysfunction with diverse signs and symptoms will then recur throughout the life of a patient, with periods of partial or complete remission and clinical stability in between. ${ }^{14}$ The majority of the patients (about $80 \%$ ) have such relapsing-remitting type of MS (RRMS) in the beginning, which after 10 or more years is followed by progressive clinical disability with or without superimposed relapses and remissions (secondary progressive MS [SPMS]). In about $20 \%$ of the patients the disease is progressive from the beginning, sometimes with superimposed relapses and remissions (primary progressive/ relapsing MS [PPMS/PRMS]). ${ }^{15}$ Neurological impairment in the patients caused by the disease is quantified by the Kurtzke Expanded Disability Status Scale (EDSS) ${ }^{16}$ score: EDSS score from 0.0 to 2.5 (no or few limitations in mobility), EDSS 3.0 to 5.5 (moderate limitations in mobility), EDSS 6.0 to 7.5 (walking aid or wheelchair necessary), EDSS 8.0 to 9.5 (confined to bed) and EDSS 10 (death).

\section{Therapy of MS}

Currently, there are several therapeutic options for MS with disease-modifying properties. ${ }^{17} \mathrm{~A}$ few preparations of interferon beta (IFN- $\beta$ ) showed efficacy in decreasing frequency of relapses, especially if given early in the course of the disease; however, the disease progression to disability was not slowed. When compared head-to-head, different preparations of IFN- $\beta$ showed similar efficacy in the majority of clinical trials, with a slight dominance of interferon beta- $1 \mathrm{~b}$ (IFN- $\beta 1 b)$. Glatiramer acetate, a putative neurotrophic factor, has shown almost the same efficacy as IFN- $\beta$, and is used mostly when therapy with IFN- $\beta$ is no longer possible, due to emergence of neutralizing antibodies against it.

Natalizumab, a humanized monoclonal antibody directed against $\alpha 4$-integrin, a protein present on leukocytes, reduces transmigration of these cells to inflamed areas of brain. It reduces relapse rate in MS patients to a similar extent as IFN- $\beta$ and glatiramer, but serious adverse effects of the drug recorded in a few patients, fatal progressive multifocal leukoencephalopathy, led to restriction of natalizumab's use to cases which are resistant to treatment with both IFN- $\beta$ and glatiramer. ${ }^{17}$

After immunomodulatory therapy with IFN- $\beta$, glatiramer and natalizumab loses its efficacy in a patient with MS or he/she becomes intolerant to it, the only approved 
therapeutic option is mitoxantrone. ${ }^{18}$ Mitoxantrone is an immunosuppressant with a similar efficacy to immunomodulatory drugs, but with serious adverse effects such as cardiomyopathy or secondary leukemia. Its use is limited to patients with MS no longer responsive to immunomodulators, and its cumulative maximal dose must not exceed $100 \mathrm{mg} / \mathrm{m}^{2}$, in order to avoid toxicity. Before each administration of mitoxantrone, an ultrasonography of heart is mandatory in order to detect early adverse effects on the myocardium and stop further therapy with the drug.

\section{IFN- $\beta$ I b preparations}

A new preparation of IFN- $\beta 1 \mathrm{~b}$ for subcutaneous administration (Extavia ${ }^{\circledR}$; Novartis Pharmaceuticals UK, Limited) was approved for use in humans by the European Medicines Agency (EMEA) in May 2008, and by the Food and Drug Administration (FDA) in United States in August 2009, as a biosimilar drug (the original preparation of IFN- $\beta 1 \mathrm{~b}$, Betaseron $^{\circledR}$ [Chiron corporation, Berlex, Inc., Schering $\mathrm{AG}]$ had been approved for human use for many years, and almost all clinical trials using IFN- $\beta 1 \mathrm{~b}$ were conducted with Betaseron $^{\circledR}$ ). Extavia ${ }^{\circledR}$ is a recombinant IFN- $\beta 1$ b produced by genetic engineering from a strain of Escherichia coli. Given subcutaneously in a dose of $250 \mu \mathrm{g}$ every other day, Extavia $^{\circledR}$ is used for treatment of patients with a single demyelinating event with an active inflammatory process and with high risk of developing clinically definite MS, and for patients with severe RRMS ( $\geq 2$ relapses in 2 years) or active SPMS. ${ }^{19}$

\section{Pharmacokinetics and mechanism of action}

After subcutaneous administration, IFN- $\beta 1 \mathrm{~b}$ is slowly and irregularly absorbed (maximum serum levels are measured 1-8 hours after injection), with an absolute bioavailability of $51 \%$. It is distributed in an extracellular compartment, and degraded by the reticular-endothelial system in the liver. Total IFN- $\beta 1 \mathrm{~b}$ clearance is about $30 \mathrm{~mL} \cdot \mathrm{min}^{-1} \cdot \mathrm{kg}^{-1}$ and serum half-life around 5 hours..$^{20,21}$

IFN- $\beta 1 \mathrm{~b}$ in patients with MS binds to its specific receptors on surface of cells in the immune system, and then changes the expression of several genes. The expression of some genes is suppressed, leading to a decrease in quantity of cell-associated adhesion molecules, inhibition of major histocompatibility complex class II expression, and reduction in inflammatory cells migration into the central nervous system. Synthesis of proinflammatory cytokines is inhibited, and production of immunosuppressive ones is increased.
Finally, T cells which attack neural structures, are inhibited by IFN- $\beta 1 b^{22}$ (Figure 1 ).

\section{Efficacy Efficacy in RRMS}

Efficacy of IFN- $\beta 1 \mathrm{~b}$ was tested in several placebo-controlled, randomized, double-blind, multicenter trials. In a phase 3 trial conducted by the IFN- $\beta$ Multiple Sclerosis Study Group ${ }^{23}$ IFN- $\beta 1 \mathrm{~b}$ was given subcutaneously $(250 \mu \mathrm{g}$ or $50 \mu \mathrm{g}$ every second day) to 372 patients with EDSS score less than 5.5 and at least 2 relapses in the last 2 years. The patients were treated for 2 years, and IFN- $\beta 1 \mathrm{~b}$ reduced relapses (but only when given in higher dose $-250 \mu \mathrm{g}$ ) for $34 \%$ (1.31 exacerbations annually with placebo and 0.9 with higher dose of IFN- $\beta 1 \mathrm{~b}$ ) and made $31 \%$ more patients relapse-free for the study period (16\% relapse-free with placebo and $25 \%$ relapse-free with IFN- $\beta 1 \mathrm{~b})$. The following adverse events were related to IFN- $\beta 1$ b: myalgia, sweating, malaise, fever and injection-site reactions, like redness and pain. Injectionsite reactions were the most frequent adverse events, occurring at rate close to $70 \%$, but also relatively mild. In this study, researchers noted emergence of neutralizing antibodies against IFN- $\beta 1 \mathrm{~b}$ in blood of the patients who received this drug for prolonged periods. Up to $47 \%$ of the patients produced neutralizing antibodies, and became less responsive to IFN- $\beta 1 \mathrm{~b}$ after 18 months of therapy. The study was extended for 3 years, ${ }^{24}$ confirming sustainability of reduction in relapses after the higher dose $(250 \mu \mathrm{g})$.

\section{Efficacy in initial acute neurological dysfunction}

A large randomized, placebo-controlled, double-blind, multicenter study was conducted in 18 European countries ${ }^{25}$ on 483 patients, to test whether early treatment with $250 \mu \mathrm{g}$ of IFN- $\beta 1$ b (within 60 days of initial acute neurological dysfunction) will slow down progression of clinically isolated neurological event to clinically defined MS. After 2 years of treatment, IFN- $\beta 1 \mathrm{~b}$ reduced the risk of development of clinically defined MS from $45 \%$ (with placebo) to $28 \%$ (with IFN- $\beta 1 \mathrm{~b}$ ). IFN $\beta-1 \mathrm{~b}$ also prolonged the time to second neurological event by 363 days (255 days in the placebo group, 618 days in the IFN $\beta$-1b group). ${ }^{20}$ The study was extended for 3 more years, and all patients received IFN $\beta-1 b$, with the aim of exploring the effect of the drug on progression of disability. ${ }^{26}$ After 3 years, $37 \%$ of the patients who were receiving IFN $\beta$ - $1 \mathrm{~b}$ from the very beginning developed clinically defined MS, compared with $51 \%$ of the patients who were at first on placebo. Also, early treatment with IFN $\beta-1 b$ 


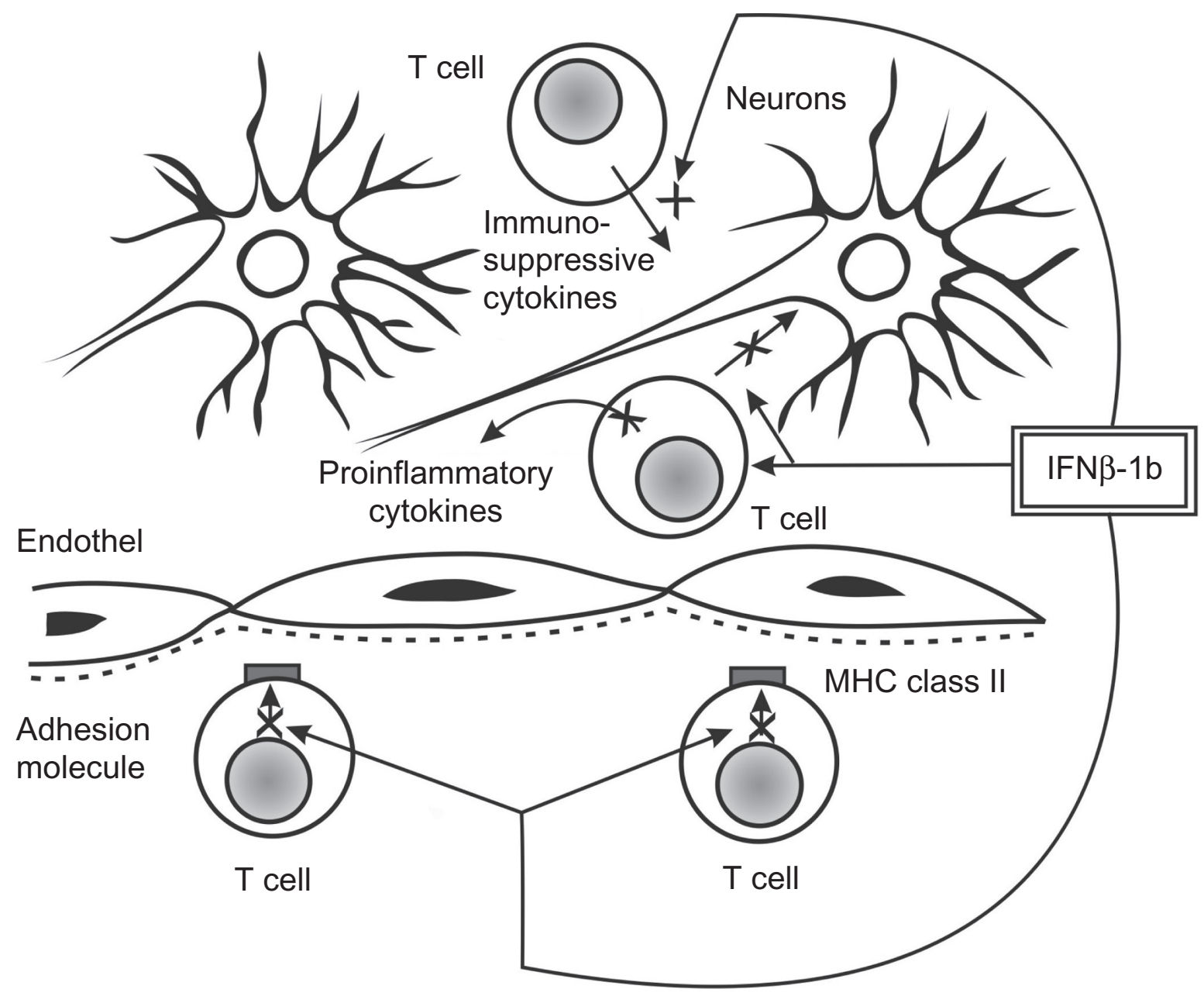

Figure I Mechanism of action of interferon beta- Ib.

resulted with only $16 \%$ percent of patients who developed progression of disability, while $24 \%$ of patients who were at first on placebo and later on IFN $\beta-1 b$ experienced progression of EDSS score.

\section{Efficacy in SPMS}

In two studies (European ${ }^{27}$ and North American ${ }^{28}$ ) IFN- $\beta 1 \mathrm{~b}$ ( $250 \mu \mathrm{g}$ subcutaneously every second day, for 2 years) was tested in patients with SPMS. Only in the European study time to increase in the EDSS score for 1 point was longer in IFN group compared with placebo group, ie, annual rate of progression was $16 \%$ in IFN group compared with $19 \%$ in placebo group. The difference was not significant in the North American trial. Also, the mean annual relapse rate in the European study was lower in the IFN- $\beta 1$ b group (0.42) than in placebo group (0.63). Despite conflicting results of these two studies, IFN- $\beta 1 \mathrm{~b}$ was approved by the FDA and the EMEA for treatment of SPMS.

\section{Comparison with IFN- $\beta$ Ia}

The efficacy of IFN- $\beta 1 b$ in MS was compared with efficacy of IFN- $\beta 1$ a in 156 patients with RRMS. The patients with initial value of EDSS score less than 4 were followed for $12^{29}$ and $18^{30}$ months, and relapse rate was the primary outcome. Although the relapse rate before enrollment of the patients was similar in both IFN- $\beta 1 \mathrm{a}$ and IFN- $\beta 1 \mathrm{~b}$ group, after 12 months of treatment relapse rate in IFN- $\beta 1$ broup was significantly lower ( 0.61 per year) than relapse rate in IFN- $\beta 1 \mathrm{~b}$ group ( 0.85 per year). Besides, after 12 months of treatment, only IFN- $\beta 1 \mathrm{~b}$ significantly reduced the EDSS score. Dominance of IFN- $\beta 1 \mathrm{~b}$ over IFN- $\beta 1$ a was maintained after 18 months of follow-up. ${ }^{30}$

Higher efficacy of IFN- $\beta 1$ b compared to IFN- $\beta 1$ a was also shown in a multicenter, randomized clinical trial with 188 patients with RRMS. ${ }^{31}$ The patients were treated for 2 years, with either $30 \mu \mathrm{g}$ of IFN- $\beta 1$ a per week subcutaneously, or with $250 \mu \mathrm{g}$ of IFN- $\beta 1 \mathrm{~b}$ every other day, subcuta- 
neously. After 2 years, $51 \%$ of study patients who received IFN- $\beta 1 \mathrm{~b}$ remained relapse-free compared to $36 \%$ of study patients who were given IFN- $\beta 1$ a (relative risk of relapse $0.76)$.

\section{Comparison with glatiramer acetate}

When compared with glatiramer acetate in patients with RRMS, IFN- $\beta 1 \mathrm{~b}$ showed similar efficacy. In a large, randomized, prospective, multicenter clinical trial ${ }^{32}$ with 2447 patients suffering from RRMS, 3-year therapy with $250 \mu \mathrm{g}$ of IFN- $\beta 1 \mathrm{~b}$ every other day, subcutaneously, led to the same relapse rate as $500 \mu \mathrm{g}$ of IFN- $\beta 1 \mathrm{~b}$ every other day, subcutaneously, or $20 \mu \mathrm{g}$ of glatiramer acetate subcutaneously, every day. Small clinical study with 75 patients, which compared IFN- $\beta 1 \mathrm{~b}$ with glatiramer in patients with RRMS, had for primary outcome number of combined active lesions on NMR per patient per scan during the first year, including all enhancing lesions and non-enhancing new T2/fluid-attenuated inversion recovery lesions, and for secondary outcomes the number of new lesions and clinical exacerbations over 2 years. After completion of the study, there were no differences among the groups in new lesions or clinical relapses for 2 years. ${ }^{33}$

\section{Dosing schedule of IFN- $\beta$ I b}

Patients with RRMS should receive initially $62.5 \mu \mathrm{g}$ subcutaneously every other day for 3 doses; then the dose should be doubled and given every other day for the next 3 occasions. The following 3 doses are given also every other day subcutaneously, and are 3 times higher than the initial dose. Finally, the patients continue to receive $250 \mu \mathrm{g}$ every other day subcutaneously, for approximately 5 years. The dose of $250 \mu \mathrm{g}$ every other day was shown to be more effective in clinical trials than either the lower or higher doses. ${ }^{23-25,27,28}$ It is not known yet whether the therapy should be continued after 5 years. ${ }^{17,19}$

\section{Safety and tolerability}

In recommended doses IFN- $\beta 1 \mathrm{~b}$ causes the following frequent adverse effects (frequency is given in parenthesis): injection site reactions (redness, discoloration, inflammation, pain, necrosis and non-specific reactions) (85\%), insomnia (31\%), influenza-like syndrome (34\%), asthenia (34\%), headache (32\%), myalgia (26\%), hypoesthesia (26\%), nausea $(16 \%)$, paresthesia $(16 \%)$, myasthenia (11\%), chills $(8 \%)$, depression $(8 \%)$, back pain $(5 \%)$, increased liver enzymes $(11 \%)$, lymphopenia $(11 \%)$, fever $(5 \%)$, and pain in extremities $(3 \%) \cdot{ }^{34,35}$ In pediatric populations, the most common adverse events recorded in clinical trials are influenza-like syndrome (35\%), abnormal liver function tests (26\%), and injection site reactions $(21 \%) .{ }^{36}$ During treatment with IFN- $\beta 1 \mathrm{~b}$, a number of patients develop neutralizing antibodies; however, their clinical significance was not proven in clinical studies, making the utility of measuring neutralizing antibodies uncertain, ${ }^{37}$ leaving decisions about treatment with IFN- $\beta 1 \mathrm{~b}$ to be made on clinical grounds. ${ }^{38}$ Apart from neutralizing antibodies, about $7 \%$ of patients during treatment with IFN- $\beta 1$ b develop auto-antibodies, primarily against thyroid and hepatic structures. ${ }^{39}$ However, emergence of the auto-antibodies was not linked to thyroid or liver function alterations. ${ }^{40}$

Although there are no published studies of interactions between IFN- $\beta 1 \mathrm{~b}$ and other drugs, there are reports that IFNs reduce the activity of hepatic cytochrome P450-dependent enzymes. ${ }^{19}$ Therefore, one should be careful when using IFN- $\beta 1 b$ in combination with drugs which are metabolized by the cytochrome P450 system, and whose therapeutic index is narrow.

Patients receiving IFN- $\beta 1 \mathrm{~b}$ perceive depression, influenza-like reactions and pain due to injection site reactions as most disturbing. ${ }^{41}$ When starting an IFN- $\beta 1 \mathrm{~b}$ therapy, a treatment discontinuation rate ranging from $14 \%-44 \%$ could be expected..$^{42}$ However, there is a considerable inter-individual variation among patients in perception of both the systemic and local side-effects, which is why it is important to identify early the patients who need more support or other interventions to maintain compliance. ${ }^{43}$ Patient adherence is improved dramatically if the drug is administered subcutaneously by auto-injectors; besides, if the dose is gradually increased at the start of the treatment, if ibuprofen is used prophylactically and the drug is administered in the evening, the patients are more compliant. ${ }^{37}$ The patients with MS dependent on a wheelchair are at increased risk to become non-adherent to the treatment due to the adverse effects of IFN- $\beta 1 b$.

If a patient receiving IFN- $\beta 1 \mathrm{~b}$ becomes depressed, treatment of the depression with either psychotherapy or antidepressant medication decreases risk of discontinuing IFN- $\beta 1 b$ by about 4.4 -fold. ${ }^{44}$ Psychotherapy is used as a treatment option more frequently in university and academic group practice-based MS clinics than in a regular health system.

\section{Cost/effectiveness of IFN- $\beta$ I b}

Because of the considerable cost of IFN- $\beta 1 \mathrm{~b}$ therapy its cost/effectiveness is still an open issue, which depends on duration of therapy, an accurate estimate of long-term benefit and prices of health services in health care settings. In US health care settings, if IFN- $\beta 1 \mathrm{~b}$ is given for the lifetime of a 
patient, incremental cost per quality-adjusted life year gained (compared to symptom management alone) is $\$ 310,691$, which is within the range of incremental cost/effectiveness recorded for other biologic agents for MS (\$258,465, \$303,968 and $\$ 416,301$ for subcutaneous glatiramer, intra-muscular IFN- $\beta 1 \mathrm{a}$ and subcutaneous IFN- $\beta 1 \mathrm{a}$, respectively). ${ }^{45}$ If the costs are calculated per relapse avoided in patients with RRMS, IFN- $\beta 1 \mathrm{~b}$, subcutaneous IFN- $\beta 1 \mathrm{a}$ and glatiramer are more favorable than intra-muscular IFN- $\beta 1$ a $(\$ 87,061$; $\$ 80,589$ and $\$ 88,310$; respectively). ${ }^{46}$ When IFN- $\beta 1 \mathrm{~b}$ is used in some of the European Union (EU) countries for 20 years, the costs per quality-adjusted life-year gained will be less than $€ 50,000$. Large differences in costs between the US and the EU could be explained by much higher prices of drug administration services in the USA. ${ }^{47}$ However, if IFN- $\beta 1 \mathrm{~b}$ and other biologic agents are used for patients in a country passing through socio-economic transition, neither IFN- $\beta 1$ b nor other biologic agents are cost/effective, due to extremely low prices of relapse treatment, which is prevented by IFN- $\beta 1 b .{ }^{48}$

\section{Tolerance to IFN- $\beta$ I b}

After at least 1 year of IFN- $\beta 1 \mathrm{~b}$ therapy, ${ }^{49}$ about one fifth of the patients with MS develop tolerance to this drug, manifested as an increase in the relapse rate. ${ }^{50}$ The tolerance correlates well with emergence of neutralizing antibodies, which are produced by the patient's immune system and bind to IFN- $\beta 1 \mathrm{~b}$, preventing its action. ${ }^{51}$ It was noted that this tolerance spontaneously abates after several years of continuous treatment, coinciding with disappearance of neutralizing antibodies from the patients' sera. ${ }^{20}$ Therefore, a finding of neutralizing antibodies against IFN- $\beta 1 \mathrm{~b}$ in serum of MS patients is not an indication for discontinuing therapy with this valuable drug.

\section{Conclusions}

Extavia $^{\circledR}$, an IFN- $\beta 1 \mathrm{~b}$ for subcutaneous self-administration, was recently approved for treatment of relapsing-remitting or active secondary progressive MS, thus enlarging the spectrum of immunological therapies for this debilitating disease. Its efficacy in RRMS is higher than that of IFN- $\beta 1 \mathrm{a}$, and similar to the efficacy of glatiramer acetate. Higher efficacy and similar safety compared with other drugs of the same class, mean that IFN- $\beta 1 b$ has a significant segment of the drug market for MS, which is shared between the older product Betaseron $^{\circledR}$ and Extavia ${ }^{\circledR}$. Considering the high incidence of injection site reactions to IFN- $\beta 1 \mathrm{~b}$, a future target should be the development of an IFN- $\beta 1 \mathrm{~b}$ preparation with improved local tolerability and maintained systemic efficacy.

\section{Acknowledgments/disclosures}

This work was partially funded by a research grant No 145005 given by Ministry of Science, Republic of Serbia. The author is grateful to Mr Milan Novakovic and Mr Milos Stojanovic for helping him in technical processing of the Figure 1.

The author declares no conflicts of interest in relation to the work reported.

\section{References}

1. Nielsen JM, Korteweg T, Polman CH. Diagnosing MS: recent guidelines and future goals focusing on magnetic resonance imaging. Int MS J. 2007;14:29-34.

2. Aminoff MJ. Nervous system disorders. In: McPhee SJ, Papadakis MA, Editors Current Medical Diagnosis and Treatment, 48th edition, New York: McGraw Hill Medical; 2009. p. 848-911.

3. Poser CM, Brinar VV. The accuracy of prevalence rates of multiple Sclerosis: a critical review. Neuroepidemiology. 2007;29:150-155.

4. Fox CM, Bensa S, Bray I, Zajicek JP. The epidemiology of multiple sclerosis in Devon: a comparison of the new and old classification criteria. J Neurol Neurosurg Psychiatry. 2004;75:56-60.

5. Al-Hashel J, Besterman AD, Wolfson C. The prevalence of multiple sclerosis in the Middle East. Neuroepidemiology. 2008;31:129-137.

6. Rivera VM. Multiple Sclerosis in Latin America, reality and challenge. Neuroepidemiology. 2009;32:294-295.

7. Wasay M, Khatri IA, Khealani B, Sheerani M. MS in Asian countries. Int MS J. 2006;13:58-65.

8. García-Gallego A, Morera-Guitart J. Prevalence and characteristics of multiple sclerosis in the health district of the Marina Alta. Rev Neurol. 2002;34:732-737.

9. Celius EG, Smestad C. Change in sex ratio, disease course and age at diagnosis in Oslo MS patients through seven decades. Acta Neurol Scand Suppl. 2009;(189):27-29.

10. Goodin DS. The causal cascade to multiple sclerosis: a model for MS pathogenesis. PLOS ONE. 2009;4:1-12.

11. Kampman MT, Brustad M. Vitamin D: A candidate for the environmental effect in multiple sclerosis - observations from Norway. Neuroepidemiology. 2008;30:140-146.

12. Chard D, Miller D. Grey matter pathology in clinically early multiple sclerosis: evidence from magnetic resonance imaging. J Neurol Sci. 2009;282:5-11.

13. Vyshkina T, Kalman B. Autoantibodies and neurodegeneration in multiple sclerosis. Laboratory Investigation. 2008;88:796-807.

14. Confavreux C, Vukusic S, Moreau T, Adeleine P. Relapses and progression of disability in multiple sclerosis. $N$ Engl J Med. 2000;343: $1430-1438$

15. Richards RG, Sampson FC, Beard SM, Tappenden P. A review of the natural history and epidemiology of multiple sclerosis: implications for resource allocation and health economic models. Health Technol Assess. 2002;6:1-73.

16. Kurtzke JF. Rating neurologic impairment in multiple sclerosis: an expanded disability status scale (EDSS). Neurology. 1983;33: 1444-1452.

17. Multiple Sclerosis Therapy Consensus Group (MSTCG), Wiendl H, Toyka KV, Rieckmann P, Gold R, Hartung HP, Hohlfeld R. Basic and escalating immunomodulatory treatments in multiple sclerosis: current therapeutic recommendations. J Neurol. 2008;255:1449-1463.

18. Cristiano E, Arcega R, Correale J, et al. Recomendaciones para la optimización del tratamiento De la esclerosis múltiple en latinoamérica. Rev Neurol. 2007;44:494-498.

19. Extavia. Summary of Product Characteristics. European Medicines Agency, 20.05.2008. http://www.emea.europa.eu/humandocs/PDFs/ EPAR/extavia/emea-combined-h933en.pdf. Accessed Aug 12, 2009. 
20. Paolicelli D, Direnzo V, Trojano M. Review of interferon beta-1b in the treatment of early and relapsing multiple sclerosis. Biologics. 2009;3:369-376

21. Chiang J, Gloff CA, Yoshizawa CN, Williams GJ. Pharmacokinetics of recombinant interferon-beta ser in healthy volunteers and its effect on serum neopterin. Pharm Res. 1993;10:567-572.

22. Rudick RA. Disease-modifying drugs for relapsing-remitting multiple sclerosis and future directions for multiple sclerosis therapeutics. Arch Neurol. 1999;56:1079-1084.

23. IFNB Multiple Sclerosis Study Group. Interferon beta-1b is effective in relapsing remitting multiple sclerosis, I: clinical results of a multicenter, randomized, double-blind, placebo-controlled trial. Neurology. 1993;43: 655-661.

24. IFNB Multiple Sclerosis Study Group and the University of British Columbia. MS/MRI Analysis Group. Interferon beta-1b in the treatment of multiple sclerosis: final outcome of the randomized controlled trial. Neurology. 1995;45:1277-1285.

25. Trojano M, Pellegrini F, Fuiani A, et al. New natural history of interferon beta- treated relapsing multiple sclerosis. Ann Neurol. 2007;61: 300-306.

26. Kappos L, Freedman MS, Polman CH, et al; BENEFIT Study Group. Effect of early vs delayed interferon beta- $1 \mathrm{~b}$ treatment on disability after a first clinical event suggestive of multiple sclerosis: a 3-year follow-up analysis of the BENEFIT study. Lancet. 2007;370:89-97.

27. European Study Group on Interferon beta-1b in secondary progressive MS Placebo-controlled multicentre randomised trial of interferon beta- $1 \mathrm{~b}$ in treatment of secondary progressive MS. Lancet. 1998;352:1491-1497.

28. Goodkin DE; The North American SP MS Study Group. Interferon beta-1b in secondary progressive MS: clinical and MRI results of a 3 year randomized controlled trial [abstract]. Neurology. 2000;54:2352.

29. Khan OA, Tselis AC, Kamholz JA, Garbern JY, Lewis RA, Lisak RP. A prospective, open-label treatment trial to compare the effect of IFN beta-1a (Avonex), IFNbeta-1b (Betaseron), and glatiramer acetate (Copaxone) on the relapse rate in relapsing-remitting multiple sclerosis. Eur J Neurol. 2001;8:141-148.

30. Khan OA, Tselis AC, Kamholz JA, Garbern JY, Lewis RA, Lisak RP. A prospective, open-label treatment trial to compare the effect of IFNbeta-1a (Avonex), IFNbeta-1b (Betaseron), and glatiramer acetate (Copaxone) on the relapse rate in relapsing - remitting multiple sclerosis: results after 18 months of therapy. Mult Scler. 2001;7:349-353.

31. Durelli L, Verdun E, Barbero P, et al; Independent Comparison of Interferon (INCOMIN) Trial Study Group. Every-other-day interferon beta-1b versus once-weekly interferon beta-1a for multiple sclerosis: results of a 2-year prospective randomised multicentre study (INCOMIN). Lancet. 2002;359:1453-1460.

32. O'Connor P, Filippi M, Arnason B, et al. 250 microg or 500 microg interferon beta- $1 \mathrm{~b}$ versus $20 \mathrm{mg}$ glatiramer acetate in relapsing-remitting multiple sclerosis: a prospective, randomised, multicentre study. Lancet Neurol. 2009;8:889-897.

33. Cadavid D, Wolansky LJ, Skurnick J, et al. Efficacy of treatment of MS with IFNbeta-1b or glatiramer acetate by monthly brain MRI in the BECOME study. Neurology. 2009;72:1976-1983.

34. Hurwitz BJ, Jeffery D, Arnason B, et al. Tolerability and safety profile of 12 - to 28 -week treatment with interferon beta-1b 250 and 500 microg QOD in patients with relapsing-remitting multiple sclerosis: a multicenter, randomized, double-blind, parallel-group pilot study. Clin Ther. 2008;30:1102-1112.
35. Gottesman MH, Friedman-Urevich S. Interferon beta-1b (betaseron/ betaferon) is well tolerated at a dose of 500 microg: interferon dose escalation assessment of safety (IDEAS). Mult Scler. 2006;12:271-280.

36. Banwell B, Reder AT, Krupp L, et al. Safety and tolerability of interferon beta-1b in pediatric multiple sclerosis. Neurology. 2006;66:472-476.

37. Burks J. Interferon-beta $1 \mathrm{~b}$ for multiple sclerosis. Expert Rev Neurother. 2005;5:153-164.

38. Polman C, Kappos L, White R, et al; European Study Group in Interferon Beta-1b in Secondary Progressive MS. Neutralizing antibodies during treatment of secondary progressive MS with interferon beta- $1 \mathrm{~b}$. Neurology. 2003;60:37-43.

39. Verdun E, Isoardo G, Oggero A, et al; Betaferon Safety Trial (BEST) Study Group. Autoantibodies in multiple sclerosis patients before and during IFN-beta $1 \mathrm{~b}$ treatment: are they correlated with the occurrence of autoimmune diseases? J Interferon Cytokine Res. 2002;22:245-255.

40. Durelli L, Ferrero B, Oggero A, et al; Betaferon Safety Trial (BEST) Study Group. Liver and thyroid function and autoimmunity during interferon-beta 1b treatment for MS. Neurology. 2001;57:1363-1370.

41. Twork S, Nippert I, Scherer P, Haas J, Pöhlau D, Kugler J. Immunomodulating drugs in multiple sclerosis: compliance, satisfaction and adverse effects evaluation in a German multiple sclerosis population. Curr Med Res Opin. 2007;23:1209-1215.

42. Portaccio E, Amato MP. Improving compliance with interferon-beta therapy in patients with multiple sclerosis. CNS Drugs. 2009;23: $453-462$.

43. Gottberg K, Gardulf A, Fredrikson S. Interferon-beta treatment for patients with multiple sclerosis: the patients' perceptions of the side-effects. Mult Scler. 2000;6:349-354.

44. Mohr DC, Goodkin DE, Likosky W, Gatto N, Baumann KA, Rudick RA. Treatment of depression improves adherence to interferon beta-1b therapy for multiple sclerosis. Arch Neurol. 1997;54:531-533.

45. Bell C, Graham J, Earnshaw S, Oleen-Burkey M, Castelli-Haley J, Johnson K. Cost-effectiveness of four immunomodulatory therapies for relapsing-remitting multiple sclerosis: a Markov model based on long-term clinical data. J Manag Care Pharm. 2007;13:287-289.

46. Goldberg LD, Edwards NC, Fincher C, Doan QV, Al-Sabbagh A, Meletiche DM. Comparing the cost-effectiveness of disease-modifying drugs for the first-line treatment of relapsing-remitting multiple sclerosis. J Manag Care Pharm. 2009;15:543-555.

47. Kobelt G, Jönsson L, Fredrikson S. Cost-utility of interferon beta1b in the treatment of patients with active relapsing-remitting or secondary progressive multiple sclerosis. Eur J Health Econ. 2003;4:50-59.

48. Janković SM, Kostić M, Radosavljević M, et al. Cost-effectiveness of four immunomodulatory therapies for relapsing-remitting multiple sclerosis: a Markov model based on data a Balkan country in socioeconomic transition. Vojnosanit Pregl. 2009;66:556-562.

49. Gurtubay IG, Morales G, Gállego J, Martín E, Maraví E. Tolerance to interferon beta- $1 \mathrm{~b}$ amongst patients with remittent recurrent multiple sclerosis after more than one year of treatment. An Sist Sanit Navar. 1998;21:15-19.

50. Kappos L, Polman CH, Freedman MS, et al. Treatment with interferon beta- $1 \mathrm{~b}$ delays conversion to clinically definite and $\mathrm{McD}$ Donald $\mathrm{MS}$ in patients with clinically isolated syndromes. Neurology. 2006;67:1242-1249.

51. Sorensen PS, Ross C, Clemmesen KM, et al. Danish Multiple Sclerosis Study Group. Clinical importance of neutralising antibodies against interferon beta in patients with relapsing remitting multiple sclerosis Lancet. 2003;362:1184-1191.

Journal of Inflammation Research

\section{Publish your work in this journal}

The Journal of Inflammation Research is an international, peer-reviewed open-access journal that welcomes laboratory and clinical findings on the molecular basis, cell biology and pharmacology of inflammation including original research, reviews, symposium reports, hypothesis formation and commentaries on: acute/chronic inflammation; mediators of inflamma-

\section{Dovepress}

tion; cellular processes; molecular mechanisms; pharmacology and novel anti-inflammatory drugs; clinical conditions involving inflammation. The manuscript management system is completely online and includes a very quick and fair peer-review system. Visit http://www.dovepress.com/ testimonials.php to read real quotes from published authors. 